\title{
An Optimum Reverberation Time for Mosques in Bangladesh
}

\author{
Sheikh Muhammad Najmul Imam ${ }^{\mathrm{a} *}$, Nizamuddin Ahmed ${ }^{\mathrm{a}}$ and Daiji Takahashi ${ }^{\mathrm{b}}$ \\ ${ }^{a}$ Department of Architecture, Bangladesh University of Engineering \& Technology (BUET), Dhaka 1000, \\ Bangladesh and ${ }^{b}$ Graduate School of Engineering, Department of Urban and Environmental Engineering, \\ Kyoto University, Kyoto 615-8540, Japan.
}

\begin{abstract}
For a mosque in Bangladesh, the acoustical requirements in terms of intelligibility and liveliness are dissimilar for the types of sounds recitation from the Holy Koran and speech on religious subjects. To attain an overall satisfactory acoustical performance, it is significant to find an optimum Reverberation Time (RT), which is one of the important factors affecting intelligibility and liveliness. Experiment is conducted to find the effect of RT by making it a variable, while keeping other factors as non-variable and fulfilling ideal conditions for maximum intelligibility. Preferences are judged on pairs of sound clips of recitation and speech, for both intelligibility and liveliness, on a 5-point scale and findings are analysed thorough the statistical method of paired comparison. Considering preferences of all aspects the optimum RT is proposed as $0.9 \mathrm{~s}$ for an overall balanced acoustical performance for both recitation and speech for a mosque in Bangladesh.
\end{abstract}

Keywords: Intelligibility, Liveliness, Mosque, Recitation, Reverberation time, Speech.

\section{Introduction}

A mosque resembles a hall room with almost no furniture and with finish materials of low sound absorption. As a solemn worship space, it is naturally calm and quiet. For mosques in Bangladesh, there is usually a low-level of internal noise commonly produced by moving ceiling fans. In bigger mosques, sound amplification system gains needed sound level. Despite low-level of internal noise and enough sound level gained through sound amplification system, many of the mosques particularly those of large volumes have poor intelligibility, mostly because of higher RT of the space.

Sounds in a mosque might be classified in major two categories - recitation and speech. Recitation from the Holy Koran is conducted during prayers and as citation during theological speech. Speech on religious issuesis either spoken out or readout from theological scripts. The recitation is performed in Arabic, the language of its revelation. It is melodious by nature and never supported by any musical instrument. The speech, similar to a typical classroom lecture, is delivered mostly in Bangla with some adopted words from Arabic, Persian, Urdu, Turkish and English.

Intelligibility and liveliness has significant position among different factors for a quality sound. The term intelligibility refers to a qualitative term that describes the ability of an acoustic environment to transmit speech intelligibly (Morfey 2001) and it is expressed in the percentage of correctly received phrases (Maekawa 1994). The term liveliness qualifies the degree of received reverberation in a space produced by the temporal smearing of sound associated with the reverberant field (Morfey 2001), which qualifies a room as live room and a sound as live sound. On the contrary, in a dead room, the total absorbing area approaches the actual room surface area (Morfey 2001) and qualifies a sound as dead sound. Dead room or dead sound is rare in reality, while live room and live sound is common in our everyday life and we have become familiar and contented with it. Thus, liveliness has become an innate reason for preferring a sound.

We prefer higher reverberation times for music than for speech (Cremer et al. 1982). Being melodious in nature, recitation desires higher RT for liveliness and also for some added quality of divinity. Theologically, it is compulsory to listen attentively to the recitation of the Imam (prayer leader) during prayers, while getting meaning of each word is optional (Thanuvi 1990; Allah 2002). Besides, only a few Bangladeshi people understand Arabic, the language of the Holy Koran. Thus, the demand for intelligibility is much

*Corresponding Author, Email: najmul@arch.buet.ac.bd 
less in recitation. On the other hand, we are interested almost exclusively in the intelligibility of speech (Cremer et al. 1982). Because of these opposing requirements of recitation and speech, for an overall acoustical performance of a mosque, it is obvious to deduce an optimum RT that fulfils the requirements of both recitation and speech for intelligibility and liveliness.

Basing on experiments on English language, Knudsen (1929) expresses the Percentage Syllable Articulation (PSA) as,

$$
P S A=96 k_{i} k_{r} k_{n} k_{s}(\%)
$$

RT. The coefficient $k_{n}$ decreases with the increase of Signal to Noise Ratio (SNR). For a space of conventional rectangular shape, it is probable that ks does not differ noticeably from 1.0 (Knudsen 1932). Although $k_{s}$ is said to be defined by room shape, it may include other uncertain factors such as echo (Maekawa 1994).

Fig. 2 shows the relationship between Percentage Syllable Articulation (PSA) and Speech Intelligibility, where PSA and thus speech intelligibility improves as the RT decreases. Even if the syllables are not fully recognized in PSA, for the case of intelligibility, the words and phrases are rather easily understood by sequence or context (Maekawa 1994).

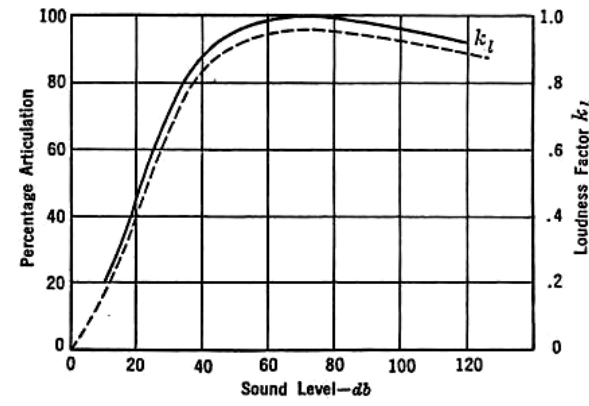

a) Solid line - Speech level coefficient

$\left(k_{i}\right)$. Dotted line - PSA vs. speech level

Fig. 1. Coefficients for Percentage Syllable Articulation (PSA). (Knudsen 1932) b) Reverberation Time coefficient $\left(k_{r}\right)$

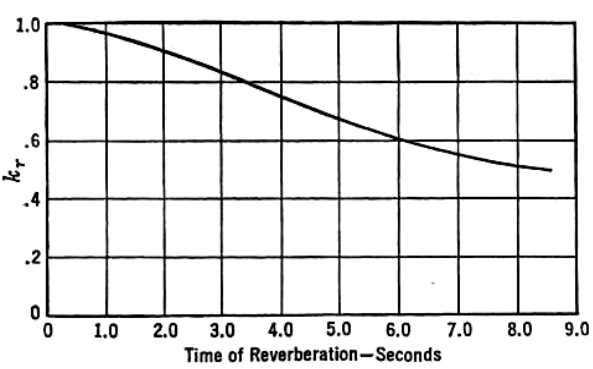

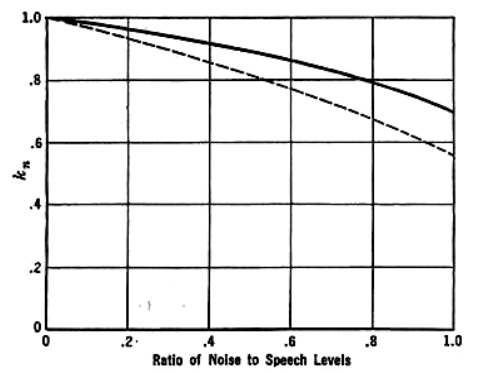

where, $\mathrm{k}_{\mathrm{i}}, \mathrm{k}_{\mathrm{r}}, \mathrm{k}_{\mathrm{n}}$ and $\mathrm{k}_{\mathrm{s}}$ are the coefficient for average speech level, Reverberation Time, Signal to Noise Ratio and room shape, respectively.

Fig. 1 shows that at an average speech level of $70 \mathrm{~dB}, k_{i}$ is maximum and it decreases rapidly below $40 \mathrm{~dB}$. At RT of $0.0 \mathrm{~s}, k_{r}$ is maximum and it decreases with the increase of

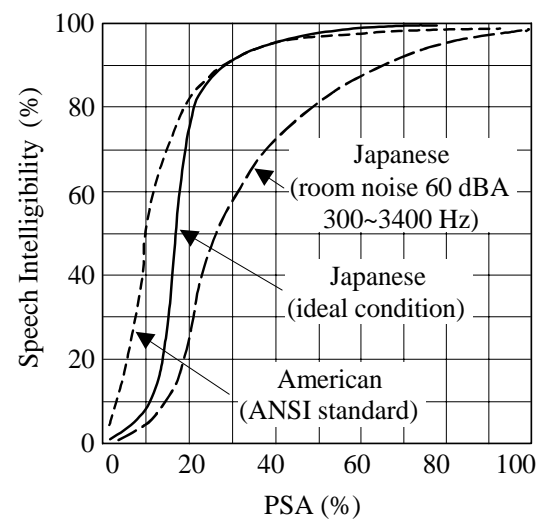

Fig. 2. PSA vs. speech intelligibility (Maekawa 1994)
For experiments, we can arrange to get coefficient for each of $k_{i}, k_{n}$ and $k_{s}$ as 1 , and make the remaining coefficient of $k_{r}$ as a variable with varying RTs. This setup can be used to find average preferences for two types of sounds (speech and recitation) with respect to intelligibility and liveliness for proposing an optimum RT.

\section{Materials and Methods}

The basic sound clips, each of a duration of $15 \mathrm{~s}$, were recorded in an anechoic chamber $(\mathrm{RT}=0.0 \mathrm{~s})$ - recitation from the Holy Koran in Arabic (Allah 2002) and speech as readout from a theology book in Bangla (Zakariah 2001). The average rates of articulation were 158 and 411 syllables per minute for recitation and speech, respectively.

Those basic sound clips were digitally convolved for different RT of 0.5, 1.0, 2.0 and $4.0 \mathrm{~s}$. Thus, including that of RT $=0.0 \mathrm{~s}$, five sound clips were prepared for each case of recitation and speech. For each case, possible pairs formed 


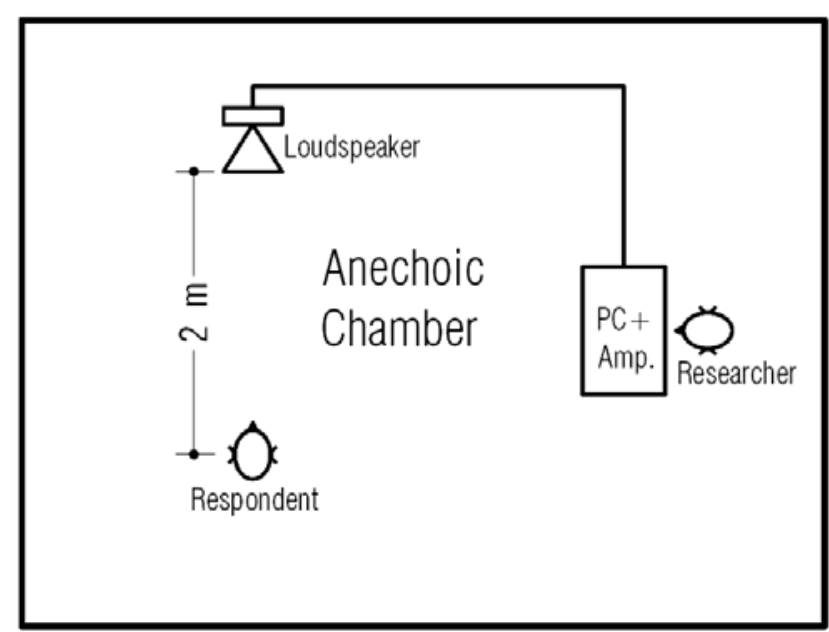

Fig. 3. Schematic plan of lab set-up in an anechoic chamber

were

$$
M=\frac{1}{2} m(m-1)
$$

Where, $m=$ number of sound clips

In this case, $m=5$. Thus, $M=10$. Each pair of sound clips, say $i$ and $j$, was played to respondents in the order $(i, j)$, and again in the reverse order $(j, i)$.

A lab was set in an anechoic chamber with a laptop PC, a high-fidelity amplifier and a loudspeaker of almost flat frequency response (Fig. 3). The sample sound clips were played back to respondents, who sat right in front of the loudspeaker at a distance of $2 \mathrm{~m}$ from the speaker.

As discussed in the preceding section, in this experiment $\mathrm{kr}$ was only variables with the varying RT. To get $k_{i}=1$, the system was set to play the sound clips at an average speech level of $70 \mathrm{~dB}$, measured at respondents position. The noise level in the anechoic chamber was very negligible and it makes $k_{n}=1$. For the rectangular shape of the anechoic chamber, we assumed, $k_{s}=1$ (Knudsen 1929).

To avail the anechoic chamber and advanced lab supports, the experiment was conducted at Kyoto University, Japan. Bangla-speaking expatriates in that vicinity took part in the experiment, three for voice recording and twelve as respondents. The sample size of respondents satisfies the underlying statistical assumptions (Scheffe 1952). The average age of the listeners was 32 years and they were screened for good hearing health through audiometry. Those who gave their voice for recording did not participate as respondents, since there would have been an obvious influence in judgment due to familiarity to one's own voice.

In a 5-point scoring scale, the respondents voted for any of the following statements on each pair in both orders $(i, j$ and $j, i)$.

I prefer 'first sound' to 'second sound' strongly (score +2)

I prefer 'first sound' to 'second sound' slightly (score +1)

No preference (score 0 )

I prefer 'second sound' to 'first sound' slightly (score -1)

I prefer 'second sound' to 'first sound' strongly (score -2)

It might be noted that the corresponding values of scores presented in the parenthesis, increases with the strength of preference in the order $i$ (first sound) to $j$ (second sound) and that for opposite order $j$ to $i$, refers to the equal but opposite (negative) score. There was a time interval after playback of each pair to efface the effects of sound from the brain, which would have otherwise influenced the perception of succeeding playbacks. In this experiment an average time interval for playbacks were maintained - one minute between pairs in similar order and ten minutes before switching to reverse order.

The respondents compared pairs and voted for both types of sample sound clips (recitation and speech) on both aspects (intelligibility and liveliness). Thus, we get four sets of data, as

a) Intelligibility in recitation

b) Liveliness in recitation

c) Intelligibility in speech

d) Liveliness in speech

The analysis of data is based on the general theory of least square and linear hypotheses similar to the statistical method adopted by Scheffe (1952). Through statistical analysis of variance (ANOVA) and F-test, significance of the main effect and order effect was judged for a confidence level of 95\%. For assessing main effects in samples of each pair, $T$ test was conducted by checking the average preferences $\hat{\alpha}_{i}$ with a yardstick for a confidence level of 95\%. From derived average preferences $\hat{\alpha}_{i}$ for varying Reverberation Time (RT), a combined graphical expression was obtained, 
which ultimately proposes an optimum reverberation time for a mosque.

\section{Results and Discussion}

For each aspect (e.g., Intelligibility in Recitation), there are two tables (e.g., Table I.a.1 and Table I.a.2) to demonstrate findings on Analysis of Variance (ANOVA) and F-Test and again T-test for a confidence level of $95 \%$ for both the cases. For T-test, using mean square for error, the yardstick is calculated. For a confidence coefficient of $1-\varepsilon=95 \%, m=5$ and $v=220$ degrees of freedom; we can find from Studentized table, $q_{0.95}=3.86$. From these data, we can calculate the yardstick $Y_{0.05}$ for each aspect.

From the second table of each aspect (e.g., Table I.a.2), we get quantitative statements on the possible differences of main effects with 95\% confidence whether all ten inequalities are true or not. The experiment demonstrates a difference for any two main effects $\alpha_{i}$ and $\alpha_{j}$, if their estimates $\hat{\alpha}_{i}$ and $\hat{\alpha}_{j}$ differ by at least the respective yardstick. The yardstick and average preferences $\hat{\alpha}_{i}$ for each aspect are shown in the notes of respective Table.

Table I.a.1. Analysis of Variance: Intelligibility in Recitation

\begin{tabular}{l|c|c|c|c|c|c}
\hline Factors & $\begin{array}{c}\text { Sum of } \\
\text { square }\end{array}$ & d.f. & Var. & $\begin{array}{c}\text { Var. } \\
\text { ratio }\end{array}$ & $\begin{array}{c}\text { F- } \\
\text { Test }\end{array}$ & $\begin{array}{c}\text { Prob. } \\
(\%)\end{array}$ \\
\hline $\begin{array}{l}\text { Main } \\
\text { effects }\end{array}$ & 496.067 & 4 & 124.017 & 798.546 & 2.413 & 0.000 \\
$\begin{array}{l}\text { Dev. from } \\
\text { subtractivity }\end{array}$ & 33.433 & 6 & 5.572 & 35.880 & 2.135 & 0.000 \\
Order & & & & & & \\
effects & 0.333 & 10 & 0.033 & 0.215 & 1.874 & 99.482 \\
Error & 34.167 & 220 & 0.155 & & & \\
Total & 564.000 & 240 & & & & \\
\hline
\end{tabular}

Table I.b.1. Analysis of variance: Intelligibility in recitation

\begin{tabular}{l|c|c|c|c|c|c}
\hline Factors & $\begin{array}{c}\text { Sum of } \\
\text { square }\end{array}$ & d.f. & Var. & $\begin{array}{c}\text { Var. } \\
\text { ratio }\end{array}$ & $\begin{array}{c}\text { F- } \\
\text { Test }\end{array}$ & $\begin{array}{c}\text { Prob. } \\
(\%)\end{array}$ \\
\hline $\begin{array}{l}\text { Main } \\
\text { Effects }\end{array}$ & 134.083 & 4 & 33.521 & 28.798 & 2.413 & 0.000 \\
$\begin{array}{l}\text { Dev. from } \\
\text { subtractivity }\end{array}$ & 8.042 & 6 & 1.340 & 1.151 & 2.135 & 33.363 \\
Order & & & & & & \\
effects & 2.792 & 10 & 0.279 & 0.240 & 1.874 & 99.188 \\
Error & 256.083 & 220 & 1.164 & & & \\
Total & 401.000 & 240 & & & & \\
\hline
\end{tabular}

For intelligibility in recitation, Table I.a.1 shows that the variance of main effects is significantly larger than the variance of error and the probability is less than $0.05 \%$. It indicates that the sound clips are adequately rated by their main effects $\alpha_{i}$. So, it asserts with 95\% confidence that the main effects are significant. On the contrary, variance of order effects is rather smaller than the variance of error and the probability is closer to $100 \%$. Thus, it states with $95 \%$ confidence that the order effects of the sound clips are insignificant. The variance of deviation from the subtractivity also suggests similarly. As a T-test in Table I.a.2, the extreme $\hat{\alpha}_{i}$ differ by more than the yardstick $Y_{0.05}=0.139$, which suggests that there exists differences in preferences of the sound clips. Further checking with the same yardstick (Table I.a.2) demonstrates differences in preferences within sound clips of each pair.

Similarly, for liveliness in recitation, Table I.b.1 shows with $95 \%$ confidence that the main effects are significant but the order effects are insignificant. The variance of deviation from the subtractivity also suggests the significance of main effects but at a relatively lower confidence level. In Table I.a.2, the extreme $\hat{\alpha}_{i}$ differ by more than the yardstick $Y_{0.05}$ $=0.380$, which suggests that there exists differences in preferences of the sound clips. But, further checking of each pair with the same yardstick (Table I.b.2), shows that the differences are not demonstrated between $\alpha_{2}$ and $\alpha_{5}$, nor between $\alpha_{3}$ and $\alpha_{4}$.

For intelligibility in speech, Table I.c.1 asserts with 95\% confidence that the main effects are significant while the order effects are insignificant. The variance of deviation from the subtractivity also suggests likewise. In Table I.c.2, the extreme $\hat{\alpha}_{i}$ differ by more than the yardstick $=0.140$, which suggests that there exists differences in preferences of the sound clips. Further checking of each pair with the same yardstick (Table I.c.2) confirms differences within sound clips of each pairs

For liveliness in speech, Table I.d.1 shows with 95\% confidence that the main effects are significant but the order effects are insignificant. The variance of deviation from the subtractivity also suggests the significance of main effects but at a relatively lower confidence level. In Table I.d.2, the extreme $\hat{\alpha}_{i}$ differ by more than the yardstick $=0.368$, which proposes that there exists differences in preferences of the sound clips. Further checking of each pair with the same yardstick (Table I.d.2), shows that the differences are not expressed between pairs $\alpha_{1}$ and $\alpha_{5}, \alpha_{2}$ and $\alpha_{3}, \alpha_{2}$ and $\alpha_{4}$, $\alpha_{3}$ and $\alpha_{4}$. 
Table I.a.2. T-test: Intelligibility in Recitation

\begin{tabular}{ccc}
\hline$\hat{\alpha}_{i}-\hat{\alpha}_{j}-\boldsymbol{Y}_{\text {a.05 }}$ & $\leq \alpha_{i}-\hat{\alpha}_{j} \geq$ & $\hat{\alpha}_{i}-\hat{\alpha}_{i}+\boldsymbol{Y}_{\text {a05 }}$ \\
\hline 0.36 & $\leq \alpha_{1}-\alpha_{2} \geq$ & 0.64 \\
\hline 0.86 & $\leq \alpha_{1}-\alpha_{3} \geq$ & 1.14 \\
\hline 1.72 & $\leq \alpha_{1}-\alpha_{4} \geq$ & 2.00 \\
\hline 2.38 & $\leq \alpha_{1}-\alpha_{5} \geq$ & 2.66 \\
\hline 0.36 & $\leq \alpha_{2}-\alpha_{3} \geq$ & 0.64 \\
\hline 1.22 & $\leq \alpha_{2}-\alpha_{4} \geq$ & 1.50 \\
\hline 1.88 & $\leq \alpha_{2}-\alpha_{5} \geq$ & 2.16 \\
\hline 0.72 & $\leq \alpha_{2}-\alpha_{4} \geq$ & 1.00 \\
\hline 1.38 & $\leq \alpha_{3}-\alpha_{5} \geq$ & 1.66 \\
\hline 0.52 & $\leq \alpha_{4}-\alpha_{5} \geq$ & 0.80 \\
\hline Notes: $\boldsymbol{Y}_{\text {aos }}=0.139 ; \hat{\alpha}_{1}=1.175$, & $\hat{\alpha}_{1}=0.675$, \\
$\hat{\alpha}_{3}=0.175, \hat{\alpha}_{4}=-0.683$ and & $\hat{\alpha}_{5}=-1.342$ \\
\hline
\end{tabular}

Table I.c.1. Analysis of variance: Intelligibility in speech

\begin{tabular}{l|c|c|c|c|c|c}
\hline Factors & $\begin{array}{c}\text { Sum of } \\
\text { square }\end{array}$ & d.f. & Var. & $\begin{array}{c}\text { Var. } \\
\text { ratio }\end{array}$ & $\begin{array}{c}\text { F- } \\
\text { Test }\end{array}$ & $\begin{array}{c}\text { Prob. } \\
(\%)\end{array}$ \\
\hline $\begin{array}{l}\text { Main } \\
\text { effects }\end{array}$ & 520.450 & 4 & 130.113 & 825.714 & 2.413 & 0.000 \\
$\begin{array}{l}\text { Dev. from } \\
\text { subtractivity }\end{array}$ & 34.550 & 6 & 5.758 & 36.543 & 2.135 & 0.000 \\
$\begin{array}{l}\text { Order } \\
\text { effects }\end{array}$ & 0.333 & 10 & 0.033 & 0.212 & 1.874 & 99.512 \\
$\begin{array}{l}\text { Error } \\
\text { Total }\end{array}$ & 34.667 & 220 & 0.158 & & & \\
\hline
\end{tabular}

Table I.c.2. T-test: Intelligibility in Speech

\begin{tabular}{ccc}
\hline$\hat{\alpha}_{i}-\hat{\alpha}_{j}-\boldsymbol{Y}_{005}$ & $\leq \alpha_{i}-\hat{\alpha}_{j} \geq$ & $\hat{\alpha}_{i}-\hat{\alpha}_{i}+\boldsymbol{Y}_{0.05}$ \\
\hline 0.44 & $\leq \alpha_{1}-\alpha_{2} \geq$ & 0.72 \\
1.14 & $\leq \alpha_{1}-\alpha_{3} \geq$ & 1.41 \\
\hline 1.81 & $\leq \alpha_{1}-\alpha_{4} \geq$ & 2.09 \\
\hline 2.47 & $\leq \alpha_{1}-\alpha_{5} \geq$ & 2.75 \\
\hline 0.55 & $\leq \alpha_{2}-\alpha_{3} \geq$ & 0.83 \\
\hline 1.23 & $\leq \alpha_{2}-\alpha_{4} \geq$ & 1.51 \\
1.89 & $\leq \alpha_{2}-\alpha_{5} \geq$ & 2.16 \\
0.54 & $\leq \alpha_{3}-\alpha_{4} \geq$ & 0.81 \\
\hline 1.19 & $\leq \alpha_{3}-\alpha_{5} \geq$ & 1.47 \\
\hline 0.52 & $\leq \alpha_{4}-\alpha_{5} \geq$ & 0.80
\end{tabular}

Notes: $\boldsymbol{Y}_{\mathrm{a} 05}=0.140 ; \hat{\alpha}_{1}=1.283, \hat{\alpha}_{2}=0.700$,

$\hat{\alpha}_{3}=0.008, \hat{\alpha}_{4}=-0.667$ and $\hat{\alpha}_{5}=-1.325$
Table I.b.2. T-test: Liveliness in Recitation

\begin{tabular}{ccc}
\hline$\hat{\alpha}_{i}-\hat{\alpha}_{j}-\boldsymbol{Y}_{\text {eas }}$ & $\leq \alpha_{i}-\hat{\alpha}_{i} \geq$ & $\hat{\alpha}_{i}-\hat{\alpha}_{j}+\boldsymbol{Y}_{\mathbf{0 0 5}}$ \\
\hline-1.21 & $\leq \alpha_{i}-\alpha_{2} \geq$ & -0.44 \\
-1.61 & $\leq \alpha_{i}-\alpha_{3} \geq$ & -0.85 \\
-1.72 & $\leq \alpha_{i}-\alpha_{4} \geq$ & -0.96 \\
-1.15 & $\leq \alpha_{1}-\alpha_{5} \geq$ & -0.39 \\
-0.79 & $\leq \alpha_{2}-\alpha_{3} \geq$ & -0.03 \\
-0.90 & $\leq \alpha_{2}-\alpha_{4} \geq$ & -0.14 \\
-0.32 & $\leq \alpha_{2}-\alpha_{5} \geq$ & -0.44 \\
-0.49 & $\leq \alpha_{5}-\alpha_{4} \geq$ & -0.27 \\
-0.09 & $\leq \alpha_{3}-\alpha_{5} \geq$ & -0.85 \\
-0.19 & $\leq \alpha_{4}-\alpha_{5} \geq$ & -0.96 \\
\hline
\end{tabular}

Notes: $\boldsymbol{Y}_{\mathbf{a 0 5}}=0.380 ; \hat{\alpha}_{1}=-0.833, \quad \hat{\alpha}_{2}=0.008$,

$\hat{\alpha}_{3}=0.400, \hat{\alpha}_{4}=0.508$ and $\quad \hat{\alpha}_{5}=-0.067$

Table I.d.1. Analysis of variance: Liveliness in speech

\begin{tabular}{l|c|c|c|c|c|c}
\hline Factors & $\begin{array}{c}\text { Sum of } \\
\text { square }\end{array}$ & d.f. & Var. & $\begin{array}{c}\text { Var. } \\
\text { ratio }\end{array}$ & $\begin{array}{c}\text { F- } \\
\text { Test }\end{array}$ & $\begin{array}{c}\text { Prob. } \\
(\%)\end{array}$ \\
\hline $\begin{array}{l}\text { Main } \\
\text { effects }\end{array}$ & 86.400 & 4 & 21.600 & 19.800 & 2.413 & 0.000 \\
$\begin{array}{l}\text { Dev. from } \\
\text { subtractivity }\end{array}$ & 3.100 & 6 & 0.517 & 0.474 & 2.135 & 82.754 \\
$\begin{array}{l}\text { Order } \\
\text { effects }\end{array}$ & 2.500 & 10 & 0.250 & 0.229 & 1.874 & 99.324 \\
$\begin{array}{l}\text { Error } \\
\text { Total }\end{array}$ & 240.000 & 220 & 1.091 & & & \\
\hline
\end{tabular}

Table I.d.2. T-test: Liveliness in Speech

\begin{tabular}{ccc}
\hline$\hat{\alpha}_{i}-\hat{\alpha}_{j}-Y_{005}$ & $\leq \alpha_{i}-\hat{\alpha}_{j} \geq$ & $\hat{\alpha}_{i}-\hat{\alpha}_{j}+Y_{005}$ \\
\hline-1.22 & $\leq \alpha_{1}-\alpha_{2} \geq$ & -0.48 \\
-1.27 & $\leq \alpha_{1}-\alpha_{3} \geq$ & -0.53 \\
-1.16 & $\leq \alpha_{1}-\alpha_{4} \geq$ & -0.42 \\
-0.53 & $\leq \alpha_{1}-\alpha_{5} \geq$ & -0.20 \\
-0.42 & $\leq \alpha_{2}-\alpha_{3} \geq$ & -0.32 \\
-0.31 & $\leq \alpha_{2}-\alpha_{4} \geq$ & -0.43 \\
-0.32 & $\leq \alpha_{2}-\alpha_{5} \geq$ & -1.05 \\
-0.26 & $\leq \alpha_{3}-\alpha_{4} \geq$ & -0.48 \\
-0.37 & $\leq \alpha_{3}-\alpha_{5} \geq$ & -1.10 \\
-0.26 & $\leq \alpha_{4}-\alpha_{5} \geq$ & -0.99
\end{tabular}

Notes: $Y_{0.05}=0.368 ; \hat{\alpha}_{1}=-0.542, \quad \hat{\alpha}_{2}=0.308$,

$\hat{\alpha}_{3}=0.358, \hat{\alpha}_{4}=0.250$ and $\hat{\alpha}_{5}=-0.375$ 
Average preferences $\hat{\alpha}_{i}$ for all four aspects are tabulated in Table II and graphically compared in Fig. 4. A polynomial trendline with a reliable R-squared value is fitted for each set of data. Following observations and comments may summarise the outcome of this experiment.

Table II. Average Preferences $\left(\hat{\alpha}_{i}\right)$ for varying reverberation time (RT)

\begin{tabular}{|c|c|c|c|c|c|}
\hline Aspects & $\hat{\alpha}_{1}$ & $\hat{\alpha}_{2}$ & $\hat{\alpha}_{3}$ & $\hat{\alpha}_{4}$ & $\hat{\alpha}_{5}$ \\
\hline $\begin{array}{l}\text { a. Intelligibility in } \\
\text { recitation }\end{array}$ & 1.175 & 0.675 & 0.175 & -0.683 & -1.342 \\
\hline $\begin{array}{l}\text { b. Liveliness in } \\
\text { recitation }\end{array}$ & -0.833 & -0.008 & 0.400 & 0.508 & -0.067 \\
\hline $\begin{array}{l}\text { c. Intelligibility in } \\
\text { speech }\end{array}$ & 1.283 & 0.700 & 0.008 & -0.667 & -1.325 \\
\hline $\begin{array}{l}\text { d. Liveliness in } \\
\text { speech }\end{array}$ & -0.542 & 0.308 & 0.358 & 0.250 & -0.375 \\
\hline
\end{tabular}

Note: $\hat{\alpha}_{1}, \hat{\alpha}_{2}, \hat{\alpha}_{3}, \hat{\alpha}_{4}$ and $\hat{\alpha}_{5}$ corresponds to RT $0.0 \mathrm{~s}$, $0.5 \mathrm{~s}, 1.0 \mathrm{~s}, 2.0 \mathrm{~s}$ and $4.0 \mathrm{~s}$ respectively
The two types of sounds in a mosque, recitation and speech, are unique in terms of their inherent nature and preferences to the respondents. As shown in Table II and Fig 4, the average preference for intelligibility in recitation and intelligibility in speech decreases with the increase of corresponding RT. Average preferences for liveliness in recitation and liveliness in speech initially rise with the increase of RT until it reaches at about RT of 2.0 to $2.5 \mathrm{~s}$, but starts falling off beyond that, which happens earlier for speech than for recitation. Since in general terms, RT adds reverberance or liveliness; it might be generally assumed that more the RT more the liveliness. This assumption is proved erroneous basing on the derived data and also on the explashow extreme diversity in nature of preferences. As shown in Fig. 4 , these two critical aspects cross at about RT of 0.9 s. Other aspects, intelligibility in recitation and liveliness in speech, also cross very close to this point. Any increase or decrease from this RT value results imbalance in average preferences among all aspects, i.e., any attempt to improve preferences

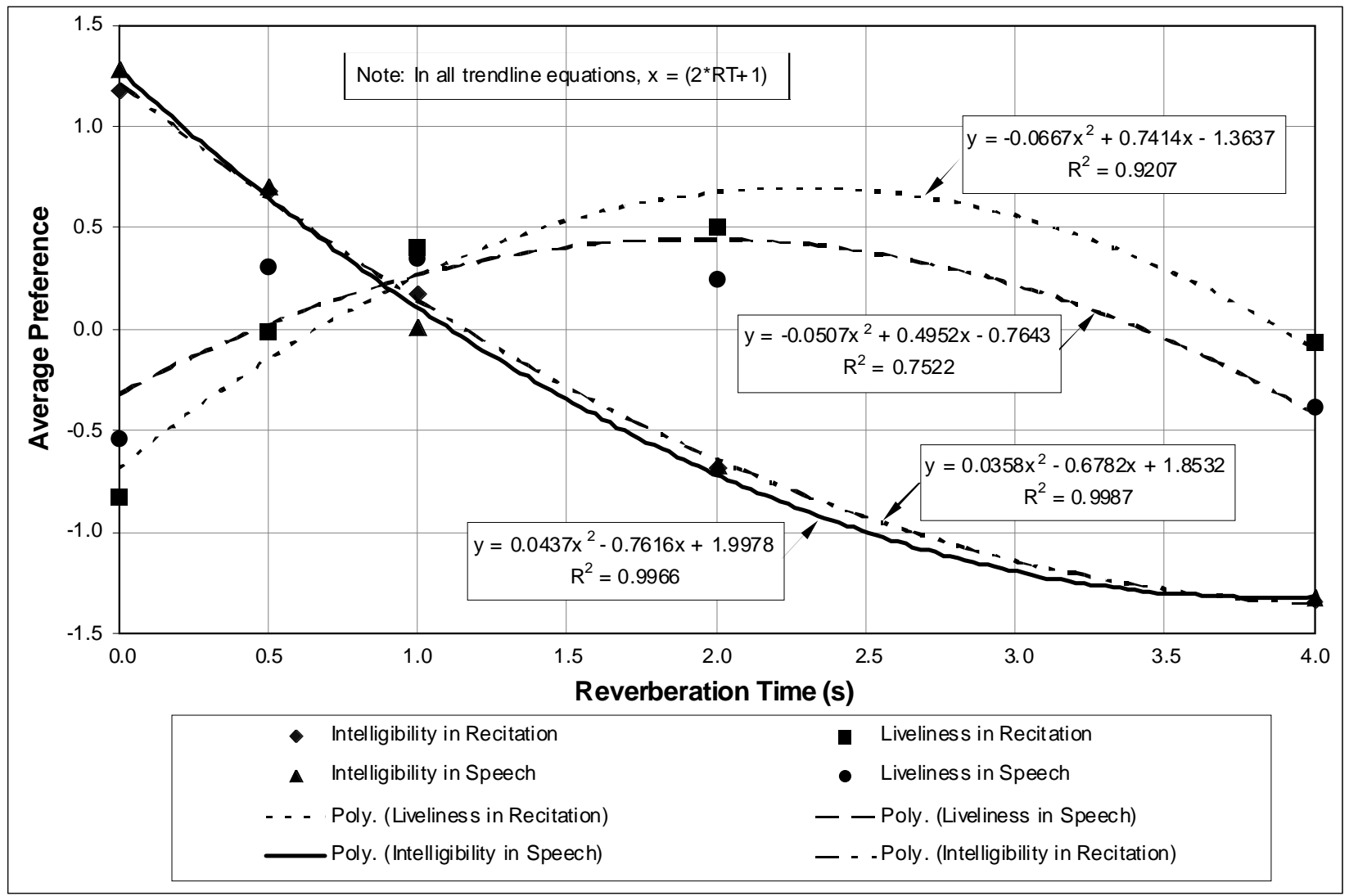

Fig. 4. Average preference for varying Reverberation Time (RT). RTs $0.0 \mathrm{~s}, 0.5 \mathrm{~s}, 1.0 \mathrm{~s}, 2.0 \mathrm{~s}$ and $4.0 \mathrm{~s}$ corresponds to $\hat{\alpha}_{1}, \hat{\alpha}_{2}, \hat{\alpha}_{3}, \hat{\alpha}_{4}$ and $\hat{\alpha}_{5}$ respectively. Trendline, related equation and $\mathbf{R}^{2}$ value is shown for each set of data 
for one aspect evidently worsen that of others. Thus, considering a balance in preferences of all aspects, the optimum RT of a mosque might be proposed as $0.9 \mathrm{~s}$.

The 'preference' in this experiment is a subjective parameter expressed in an arbitrary value ranging from a maximum of +2.0 to a minimum of -2.0. To get a tangible and objective understanding of how the proposed optimum RT affects our acoustical experience, we may refer to Percentage Syllable Articulation (PSA) and intelligibility. From Fig. 1 and Eq. 1, considering the optimum RT $=0.9 \mathrm{~s}$ in ideal conditions, where $k_{i}=1$ (for an average speech level of 70dB), $k_{r}=0.85$ (for RT $=0.9 \mathrm{~s}$ ), $k_{n}=1$ (when SNR is negligible) and $k_{\mathrm{s}}=1$ for a space of rectangular shape), we get,

$P S A=96 \times 1 \times 0.85 \times 1 \times 1 \cong 82 \%$,

From Fig. 2, for $P S A \cong 82 \%$, we get almost a perfect intelligibility (nearly 100\%) in an ideal condition. But in reality, there is usually some ambient noise in a mosque, which causes a considerable decrease in PSA and thus intelligibility.

The sound clips are adequately rated by their main effects $\alpha_{i}$ for both intelligibility and liveliness, but it is relatively larger for former than later. Moreover, the T-test with the yardstick $\mathrm{Y}_{0.05}$ demonstrates significant differences of preference $\alpha_{i}$ in all pairs for intelligibility, but it is not same in some pairs for liveliness. This expresses the fact that liveliness is relatively more subjective in nature than that of intelligibility.

Significant research is already conducted on the effects of RT on PSA and intelligibility for English language, as has been done in this paper for Bangla language. In addition, this research has included the subjective issue of liveliness to assess how it interacts with RT. The nature of growth and decay for preferences in liveliness as an effect of varying RT is a notable finding of this research.

This paper adopts the statistical methods of Scheffe (1952), which cites an example of experiment on taste-testing of food. In that case, the 'order effects' were found to be significant. For this experiment on sound, the 'order effects' are found to be insignificant. The phenomenon can be explained as the effect of taste of food remains relatively longer time to our tongue, compared to the effect of sound to our ear. Thus, the taste of first sample of food might have influenced the second one and a reverse order showed significant difference in the experiment of Scheffe (1952). Therefore, for future experiments on sounds of similar nature, it is recom- mended to skip 'reverse order'. This will save the experiment from being excessively lengthy, which will ultimately decrease the probability of erroneous and faulty responses from a respondent, due to fatigue and boredom caused by prolonged sessions.

\section{Conclusion}

The findings of this paper, particularly the optimum RT value, are expected to be useful for acoustical design of mosques in Bangladesh. The effects of speech levels and noise levels are beyond the scope this paper. It is a fact that in a mosque speech level can be controlled artificially for optimal performance. But it is almost impossible evading the effects of noise levels particularly in the mosques of Bangladesh, where a considerable level of outdoor noise penetrates through the large openings kept open for natural ventilation. Thus, there remain ample possibilities for exploring the effects of noise levels on acoustical performance of mosques in Bangladesh based on the research premises set out by this paper.

\section{Acknowledgements}

The research was jointly arranged by the Department of Architecture, BUET, Bangladesh and the Department of Urban and Environmental Engineering, Kyoto University, Japan, funded by the Japan Society for the Promotion of Science. The authors would like to acknowledge the supports from these institutions and concerned persons. The authors also express gratitude to the expatriates of Bangladesh in Kyoto, who have voluntarily participated in the experiments and to the colleagues for their helpful suggestions and comments

\section{References}

Allah (2002) The Holy Qur'an (The holy revelations of Allah for Muslims). Dhaka, Emdadia Library, Verses 7: 204, 54:8.

Cremer L., Muller H. A., and Schultz T. J. (1982) Principles and applications of Room Acoustics, Applied Science Publishers, London, Vol.1, p. 509.

Knudsen V. O. (1929) The hearing of Speech in Auditoriums. J. Acoust. Soc. Am. 1(Oct.): 56-78.

Knudsen V. O. (1932) Architectural Acoustics, John Wiley \& Sons Inc., New York, pp. 371-381. 
Maekawa Z., and Lord P. (1994) Environmental and Architectural Acoustics, E \& Fn Spon, London, pp. 3032.

Morfey C. L. (2001) Dictionary of Acoustics. Academic Press, UK, pp. 104, 202, 225.

Scheffe H. (1952) An Analysis of Variance for Paired Comparisons. J. Acoust. Soc. Am. 41(Sep.): 381-400.
Thanuvi M. A. A. (1990) Beheshti Jeor (translated version in Bangla). Emdadia Library, Dhaka, Vol. 1, p. 127.

Zakariah M. (2001) Fazail-i-'Amal (translated version in Bangla). Darul Kitab, Dhaka, Vol. 1, p. 22.

Received : September 11, 2008;

Accepted : October 08, 2008 